\title{
Feeding Attraction Activities of Amino Acids and Nitrogeneous Bases for Oriental Weatherfish ${ }^{* 1,2}$
}

\author{
Katsuhiko HARADA*3 \\ (Accepted August 6, 1984)
}

\begin{abstract}
The feeding attraction activities of a variety of amino acids and nitrogenous bases were investigated in a behavioral and statistical manner for oriental weatherfish Misgurnus anguillicaudatus. Of twenty-six authentic L-amino acids, the activities were recognized in histidine, arginine, lysine and ornithine among the basic amino acids. Especially, histidine and lysine evoked remarkably on feeding attraction behavior from the fish. About half of the neutral amino acids were found to be effective in the attraction. Among the amides, acidic and imino amino acids only asparagine induced strikingly the attraction in the fish. L-Amino acids elicited the attraction, but not D-ones. Of forty-three pure chemicals of nitrogenous bases, the activities were appreciably high in ammonia, monoethylamine, dimethylamine, trimethylamine, monoethanolamine and pyrrolidine among volatile nitrogenous bases. Especially ammonia and pyrrolidine were most potent on the attraction. In addition, the activities were also found in quaternary compounds among non-volatile nitrogenous bases.

The threshold values were estimated to be $5 \times 10^{-7} \mathrm{M}$ and $7 \times 10^{-11} \mathrm{M}$ for the representative attraction chemicals, L-histidine and ammonia, respectively.
\end{abstract}

The data presented in the previous paper $^{1 /}$ have demonstrated that the crude amino acid- and the crude volatile base-extracts from the whole body of lake prawn Palaemon paucidens elicited remarkably the feeding attraction behavior or the exploratory and feeding behavior from oriental weatherfish Misgurnus anguillicaudatus. The feeding attraction activities were found in the neutral and basic amino acid fractions of the crude amino acid-extract and in some volatile amines of the crude volatile base-extract. Accordingly it is interesting to investigate attraction activities of wide varieties of pure chemicals of amino acids and nitrogenous bases for the fish through behavioral experiments. This paper describes the results.

\section{Materials and Methods}

\section{Experimental Oriental Weatherfish}

Two hundred specimens of oriental weatherfish of $9.5 \mathrm{~cm}$ and $6.8 \mathrm{~g}$ in average total length and body weight were purchased from an aquaculture station in Shimonoseki, on May 31, 1983. Sixty individuals of the fish were transferred to an experimental aquarium reported previously. ${ }^{2)}$ The remainder of the fish was maintained in a stock aquarium to supplement the number of fish which became out of health or died during experiments. Each batch of fish was fed to satiation once daily at 16:00 with a commercial feeding stuff manufactured by Nihonhaigoshiryo Co.

\section{Authentic Amino Acids and Nitrogenous Bases}

Amino acids (guaranteed) bought from Nakarai Chemical Co. Ltd. were as follows: L- and Dhistidines, L-arginine, L- and D-lysine, DL-hydroxylysine hydrochloride and L-ornithine hydrochloride (thus far, basic amino acids), glycine, Land $\mathrm{D}$ - $\alpha$-alanines, L-valine, L-leucine, L-isoleucine, L-threonine, L-serine, DL-phosphoserine, Lmethionine, L-cystine hydrochloride, L-cysteine, DL-homocysteine, L-phenylalanine, L-tyrosine and L-tryptophan (thus far, neutral amino acids), and L-asparatic acid, L-asparagine, L-glutamic acid, L-glutamine, L-proline and L-hydroxyproline (thus far, amides, acidic and imino amino acids). Each amino acid-solution was prepared to a concentration of $75 \mathrm{mM}$ and if necessary, adjusted to $\mathrm{pH}$ 6.0-7.0 by the addition of sodium hydroxide or hydrochloric acid.

Nitrogenous bases (extra pure) got from Tokyo

*1 Contribution from Shimonoseki University of Fisheries No. 1046.

*2 Studies on the Feeding Attractant for Fishes and Shells-XI.

*3 Laboratory of Biochemistry, Department of Food Science and Technology, Shimonoseki University of Fisheries, Shimonoseki 759-65, Japan (原田勝彦：水産大学校製造学科生物化学教室). 
Kasei Co. Ltd. were as follows: monomethylamine, dimethylamine, trimethylamine, monoethylamine, diethylamine, triethylamine, $n$ - and iso-monopropylamines, $n$ - and iso-dipropylamines, $n$ - and iso-tripropylamines, $n$-, iso-, sec- and tertmonobutylamines, $n$ - and iso-dibutylamines, $n$ and iso-tributylamines, monoallylamine, diallylamine, triallylamine, iso-monoamylamine, $n$ diamylamine, n,iso-triamylamine, pyrrolidine, piperidine and ammonia (thus far, volatile nitrogenous bases), and trimethylamine oxide, betaine, choline, ammonium acetate, acetylcholine, quanidoacetic acid, urea, histamine, methylglycine, dimethylglycine and $\gamma$-aminobutyric acid (thus far, non-volatile nitrogenous bases). Each chemical was dissolved in water to a concentration of $7 \mathrm{~mm}$ and adjusted to $\mathrm{pH} 6.0-7.0$ by the addition of hydrochloric acid or sodium hydroxide.

\section{Estimation of Attraction Activity by Attraction Index}

The estimation of an attraction index $a$ (referred to as A.I. $a$ hereon) was based on applying the remaining time-course obtained from behavioral experiment to a logistic curve $y=g /\{1+$ $\exp [-r(j-a)]\}$ described previously. ${ }^{2\rangle}$ The gauze $(25 \times 25 \mathrm{~cm})$ soaked $7.5 \mathrm{~m} l$ of each solution was used as the attractant samples for estimating the A.I. $a$.

\section{Results and Discussion}

\section{Attraction Activities of Amino Acids}

The attraction activities are shown in Table 1 for twenty-six amino acids by classifying into basic, neutral, and acidic and imino ones and amides. Of the basic amino acids (Nos. 1 and 2), the activities were higher in histidine, arginine, lysine and ornithine but lower in hydroxylysine than in dummy as control. Especially histidine and lysine showed high activities. Of the neutral amino acids (Nos. 3-7), the activities were high in glycine, alanine and homocysteine, low in valine, isoleucine, threonine and phenylalanine, being intermediate in cysteine and tyrosine. Particularly alanine and homocysteine were noticed to have

Table 1. Attraction activities (A.I. $a$ ) of various kinds of L- and DL-amino acids

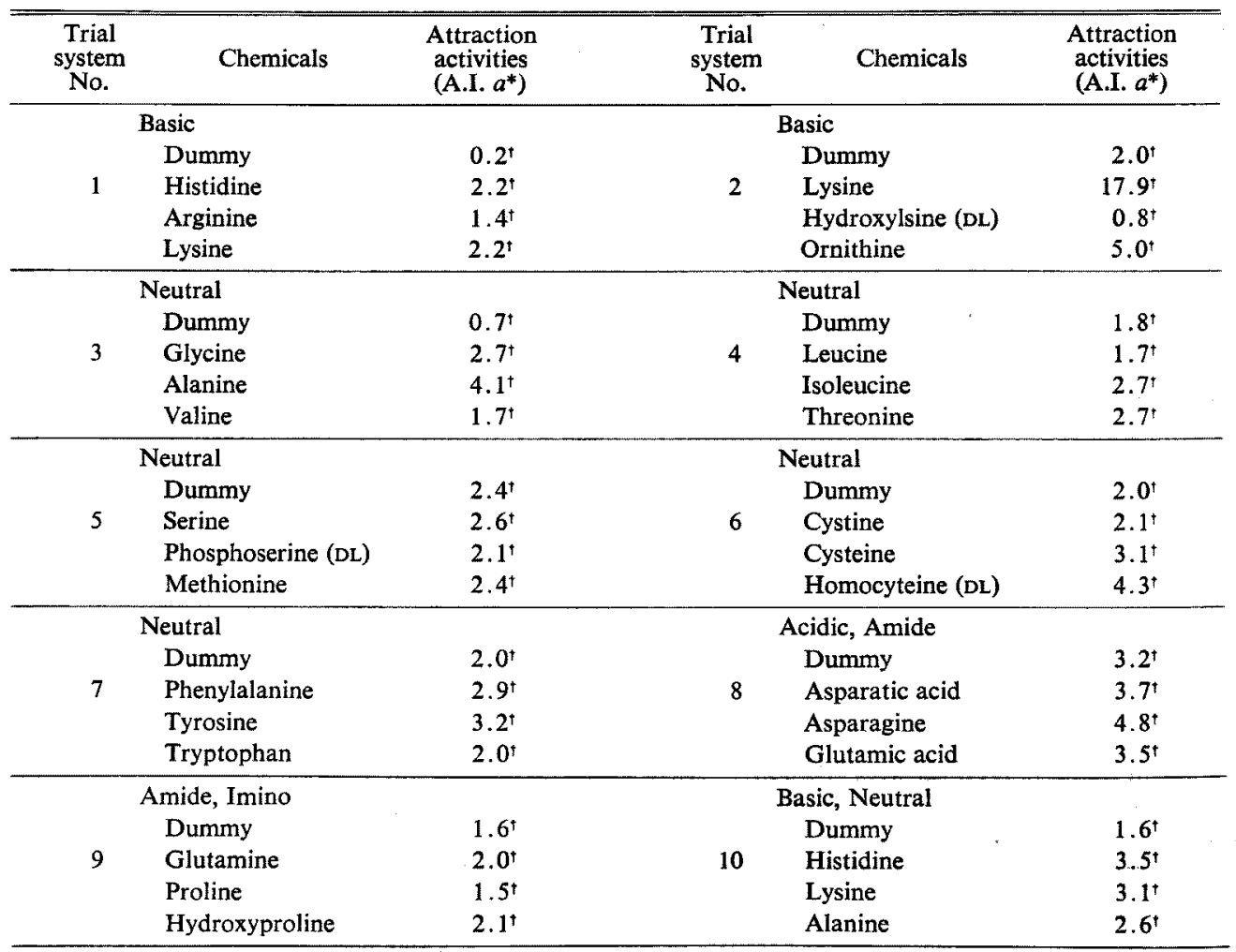

* The coefficient $a$ of a logistic curve $y=g /(1+\exp [-r(j-a)]\}$ in the remaining time-course. 2$)$

$+{ }_{1}+? \operatorname{Pr}\left(2 x>x_{0.100}^{2}\right)>0.100$ and slightly less than $\operatorname{Pr}=0.100$, respectively. $\left.{ }^{2}\right)$ 
Table 2. Attraction activities (A.I. $a$ ) of L- and D-amino acids

\begin{tabular}{|c|c|c|c|c|c|c|c|c|}
\hline $\begin{array}{c}\text { Trial } \\
\text { system } \\
\text { No. }\end{array}$ & Chemicals & $\begin{array}{l}\text { Attraction } \\
\text { activities } \\
\left(\text { A.I. } a^{*}\right)\end{array}$ & $\begin{array}{c}\text { Trial } \\
\text { system } \\
\text { No. }\end{array}$ & Chemicals & $\begin{array}{l}\text { Attraction } \\
\text { activities } \\
\text { (A.I. } a^{*} \text { ) }\end{array}$ & $\begin{array}{c}\text { Trial } \\
\text { system } \\
\text { No. }\end{array}$ & Chemicals & $\begin{array}{l}\text { Attraction } \\
\text { activities } \\
\left(\text { A.I. } a^{*}\right)\end{array}$ \\
\hline \multirow{4}{*}{11} & Dummy & 2.51 & \multirow{4}{*}{12} & Dummy & $2.2^{+}$ & \multirow{4}{*}{13} & Dummy & $2.1^{\dagger}$ \\
\hline & Glycine & $3.1^{\dagger}$ & & Glycine & $2.8^{\dagger}$ & & Glycine & $2.8^{\dagger}$ \\
\hline & L-Histidine & $10.1^{\dagger}$ & & L-Lysine & $2.9^{\prime}$ & & L-Alanine & $3.5^{\dagger}$ \\
\hline & D-Histidine & $2.7^{\dagger}$ & & D-Lysine & $1.7^{\dagger}$ & & D-Alanine & $2.0^{+}$ \\
\hline
\end{tabular}

Table 3. Attraction activities (A.I. a) of various kinds of volatile nitrogenous bases

\begin{tabular}{|c|c|c|c|c|c|}
\hline $\begin{array}{c}\text { Trial } \\
\text { system } \\
\text { No. }\end{array}$ & Chemicals & $\begin{array}{l}\text { Attraction } \\
\text { activities } \\
\left.\text { (A.I. } a^{*}\right)\end{array}$ & $\begin{array}{c}\text { Trial } \\
\text { system } \\
\text { No. }\end{array}$ & Chemicals & $\begin{array}{l}\text { Attraction } \\
\text { activities } \\
\text { (A.I. } a^{*} \text { ) }\end{array}$ \\
\hline \multirow{4}{*}{14} & Dummy & $1.2^{\dagger}$ & \multirow{4}{*}{15} & Dummy & $1.8^{\dagger}$ \\
\hline & Monomethylamine & $3.4^{\dagger}$ & & Monoethylamine & $2.0^{+}$ \\
\hline & Dimethylamine & $2.0^{\prime}$ & & Diethylamine & $2.0^{\dagger}$ \\
\hline & Trimethylamine & $3.0^{+}$ & & Triethylamine & $0.9^{t}$ \\
\hline \multirow{4}{*}{16} & Dummy & $4.2^{\dagger}$ & \multirow{4}{*}{17} & Dummy & $3.3^{t}$ \\
\hline & $n$-Monopropylamine & $3.5^{\dagger}$ & & iso-Monopropylamine & $2.3^{\dagger}$ \\
\hline & $n$-Dipropylamine & $3.3^{\prime}$ & & iso-Dipropylamine & $2.0^{+?}$ \\
\hline & n-Tripropylamine & $2.9^{t}$ & & iso-Tripropylamine & $2.6^{\dagger}$ \\
\hline \multirow{4}{*}{18} & Dummy & $3.7^{t}$ & \multirow{4}{*}{19} & Dummy & $4.3^{t}$ \\
\hline & n-Monobutylamine & $3.2^{\prime}$ & & iso-Monobutylamine & $4.0^{+}$ \\
\hline & $n$-Dibutylamine & $2.4^{t}$ & & iso-Dibutylamine & $2.9^{t}$ \\
\hline & $n$-Tributylamine & $2.6^{\dagger}$ & & iso-Tributylamine & $2.2^{\dagger}$ \\
\hline \multirow{4}{*}{20} & Dummy & $3.8^{1}$ & \multirow{4}{*}{21} & Dummy & $2.0^{\dagger}$ \\
\hline & n-Monobutylamine & $4.2^{\dagger}$ & & Monoethanolamine & $2.7^{\dagger}$ \\
\hline & sec-Monobutylamine & $4 \cdot 1^{\dagger}$ & & Diethanolamine & $2.2^{\dagger}$ \\
\hline & tert-Monobutylamine & $2.5^{t}$ & & Triethanolamine & $1.9^{r}$ \\
\hline \multirow{4}{*}{22} & Dummy & $3.9^{+}$ & \multirow{4}{*}{23} & Dummy & $4.4^{t}$ \\
\hline & Monoallylamine & $2.2^{\dagger}$ & & $n$-Monoamylamine & $3.1^{t}$ \\
\hline & Diallylamine & $1.4^{\dagger}$ & & n-Diamylamine & $3.1^{t}$ \\
\hline & Triallylamine & $2.4^{\prime}$ & & $n$,iso-Triamylamine & $3.2^{t}$ \\
\hline \multirow{4}{*}{24} & Dummy & $2.7^{\dagger}$ & \multirow{4}{*}{25} & Dummy & $2.3^{t}$ \\
\hline & Pyrrolidine & $3.6^{\dagger}$ & & Ammonia & $4.9^{\circ}$ \\
\hline & Piperidine & $2.4^{+}$ & & Pyrrolidine & $2.3^{+}$ \\
\hline & Ammonia & $4.9^{\dagger}$ & & Trimethylamine & $3.0^{+}$ \\
\hline
\end{tabular}

Signs; see footnote in Table 1.

high attraction activities. Of the acidic and imino amino acids and amides (Nos. 8 and 9), the activity was obviously high only in asparagine. In comparison with the three chemicals having the high attraction activities (No. 10), histidine and lysine were more potent than alanine. From the above results it was demonstrated that many of basic amino acids elicit strongly the attraction behavior from the fish and some of neutral amino acids are also involved in the attraction. This finding holds the previous results that the attraction activities were higher in the basic amino acidfraction than in the neutral amino acid-one. ${ }^{1)}$ In this context, the main attractants for yellowtail are considered to be basic amino acids. In referring to the review in the preceding paper, ${ }^{3)}$ it is, however, reported that the kinds of amino acids concerning on the attraction behavior depend on the species of experimental fish.

With respect to the difference in the attraction activities between $L-$ and $D$-amino acids, the results are shown in Table 2 for $L$ - and D-histidines, $L$ and D-lysines, and L- and D-alanines (Nos. 11-13). It was ascertained that the attraction activities were presented in L-amino acids but not in D-types. This accorded with the results obtained from the yellowtail experiments in which $\mathrm{L}$ - and $\mathrm{D}$-histidines, and $\mathrm{L}$ - and $\mathrm{D}$-threonines were used. ${ }^{3)}$ 
Attraction Activities of Nitrogenous Bases

The attraction activities are shown in Table 3 for thirty-two volatile nitrogenous bases, mainly volatile amines. Of the aliphatic amines (Nos. 14-23), the activities were high in monomethylamine, dimethylamine and trimethylamine, and slightly high in monoethanolamine. In particular, monomethylamine and trimethylamine showed high attraction activity. Of the imines and ammonia (No. 24), the activities were presented in pyrrolidine and ammonia, especially the latter showed strong activity. In comparison among the potent compounds (No. 25), the activities were high in ammonia, low in pyrrolidine, being intermediate in trimethylamine.

Ammonia and trimethylamine are widely distributed in the tissues of fish and shellfish. ${ }^{4-7}$ On the contrary, dimethylamine, monoethanolamine and pyrrolidine are detected only in the tissues of limited species of fishes. ${ }^{7,8)}$ Accordingly, it seems that only naturally occuring volatile bases are involved in the attraction behavior for oriental weatherfish.

Among the effective chemicals it is known that ammonia and dimethylamine or monoethylamine are effective in the attraction behavior for silverside Hepsitia stipes ${ }^{9)}$ and lamprey Petromyzon marinus, ${ }^{10)}$ respectively. On the other hand, aliphatic amines containing trimethylamine are not effective in the attraction behavior for silverside, ${ }^{8)}$ lamprey, ${ }^{11}$ pigfish Orthopristis chrysopterus, ${ }^{12)}$ turbot Scophthalmus maximus ${ }^{13)}$ and sea bream Chrysophrys major. ${ }^{14,15)}$ In this context, it is conceivable that ammonia and/or some aliphatic amine attract benthic fishes such as oriental weatherfish and lamprey, and also silverside which is said to inhabit in shoals, though the behavior of the fish resembles that of pelagic fish. ${ }^{\text {) }}$

As shown in Table 4, of the non-volatile nitrogenous bases (Nos. 26-29), the activities were high in $\gamma$-aminobutyric acid, low in acetylcholine and quanidoacetic acid, being intermediate in trimethylamine oxide, choline and histamine. In comparison among the three chemicals (No. 30), the activities were higher in trimethylamine oxide and histamine than in choline. The locomotion of the fish for histamine was, however, abnormal, i.e., the fish showed violent movement entering into and leaving from the test compartment of an experimental aquarium. Thus the attraction activity of histamine waits further examination.

There are many researches concerning the attraction activities of quaternary ammonium bases, ${ }^{13-22)}$ but a few on other bases. ${ }^{8,14,15)}$ Trimethylamine oxide is not effective in all fish recorded in litheratures, pigfish, ${ }^{12)}$ sea bream, ${ }^{14,15}$ ? turbot $^{13)}$ and European eel Anguilla anguilla. ${ }^{22)}$ The present results for trimethylamine oxide were different from those mentioned above. The reason of the discrepancy is not clear at present. There is also no common finding for the attraction activity of betaine; betaine was effective in the attraction behavior for pigfish, ${ }^{12,19)}$ pinfish Lagodon rhmoboides, ${ }^{17}$ ) adult dover sole Solea solea, ${ }^{20)}$ and Japanese eel $A$. japonica, ${ }^{21)}$ but ineffective for turbot, ${ }^{13)}$ sea bream, ${ }^{14)}$ Japanese eel, ${ }^{1{ }^{13}}$ juvenile dover sole ${ }^{202}$ and European eel. ${ }^{22)}$ Accordingly it seems that the attraction activity of betaine varies on species and size of fish ${ }^{20)}$ and also on experimental method. ${ }^{14,16,21)}$

Table 4. Attraction activities (A.I. $a$ ) of various kinds of non-volatile nitrogenous bases

\begin{tabular}{|c|c|c|c|c|c|}
\hline $\begin{array}{c}\text { Trail } \\
\text { system } \\
\text { No. }\end{array}$ & Chemicals & $\begin{array}{l}\text { Attraction } \\
\text { activities } \\
\left(\text { A.I. } a^{*}\right)\end{array}$ & $\begin{array}{l}\text { Trial } \\
\text { system } \\
\text { No. }\end{array}$ & Chemicals & $\begin{array}{l}\text { Attraction } \\
\text { activities } \\
\text { (A.I. } a^{*} \text { ) }\end{array}$ \\
\hline \multirow{4}{*}{26} & Dummy & $2.2^{\dagger}$ & \multirow{4}{*}{27} & Dummy & $1.6^{\dagger}$ \\
\hline & Trimethylamine oxide & $3.3^{\dagger}$ & & Ammonium acetate & $0.3^{+}$ \\
\hline & Betaine & $1.9^{\dagger}$ & & Choline & $3.1^{\dagger}$ \\
\hline & Choline & $3.3^{\dagger}$ & & Acetylcholine & $2.1^{\dagger}$ \\
\hline \multirow{4}{*}{28} & Dummy & $1.1^{*}$ & \multirow{4}{*}{29} & Dummy & $2.2^{\dagger}$ \\
\hline & Guanidoacetic acid & $1.6^{t}$ & & Methylglycine & $2.2^{\dagger}$ \\
\hline & Urea & $1.4^{\dagger}$ & & Dimethylglycine & $0.4^{\dagger}$ \\
\hline & Histamine & $2.3^{\dagger}$ & & $\gamma$-Aminobutyric acid & $5.9^{\dagger}$ \\
\hline \multirow{4}{*}{30} & Dummy & $1.1^{\dagger}$ & & & \\
\hline & Trimethylamine oxide & $3.9^{4}$ & & & \\
\hline & Choline & $2.2^{t}$ & & & \\
\hline & Histamine & $4.3^{\dagger}$ & & & \\
\hline
\end{tabular}

Signs; see footnote in Table 1. 


\section{Threshold Values of Histidine and Ammonia}

In order to estimate the threshold values of L-histidine and ammonia, the attraction activities in six concentrations were tested. Figs. 1 and 2 show the semi-logarithmic plots of the dose-attraction index relationships in histidine and ammonia, respectively. The ratio $a_{i} / a_{j}$ at each concentration is denoted on ordinate $(=y)$, where $a_{i}$ is $a$ of attractant sample and $a_{j}$ is that of dummy,

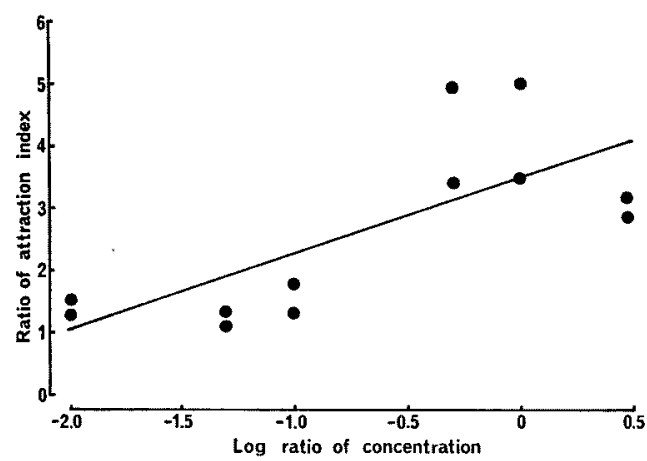

Fig. 1. The correlation between the ratio of attraction index and the logarithmic ratio of concentration in L-histidine.

Abscissa; The logarithmic ratio of each concentration to the concentration $(75 \mathrm{~mm})$.

Ordinate; The ratio of $a$ at each concentration to that of dummy.

Regression line estimated; $y=3.4521+1.2151 x$ $\left(n=12, F=11.472^{* *}\right.$, two asterisks: significant at 0.01 level).

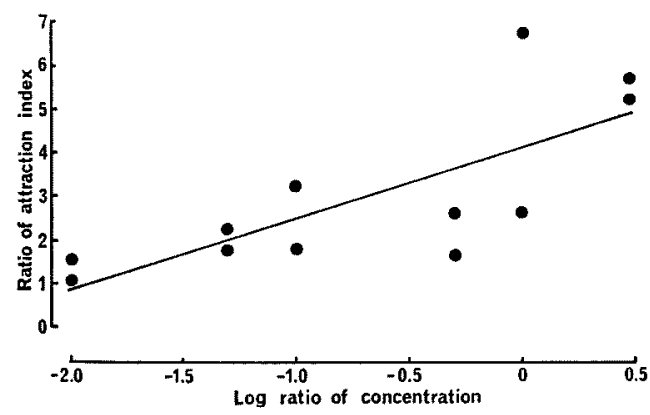

Fig. 2. The correlation between the ratio of attraction index and the logarithmic ratio of concentration in ammonia.

Abscissa; The logarithmic ratio of each concentration to the concentration (7 mM).

Ordinate; The ratio of $a$ at each concentration to that of dummy.

Regression line estimated; $y=4.1448+1.6288 x$ ( $n=12, F=12.153^{* *}$, two asterisks: significant at 0.01 level). while the logarithmic value of relative concentration (histidine, $75 \mathrm{~mm}$; ammonia, $7 \mathrm{~mm}$ ) as standard on absissa $(=x)$. From the results of a regression analysis ${ }^{23)}$ it was estimated that the regression lines are $y=3.4521+1.2151 x$ in histidine and $y=4.1448+1.6288 x$ in ammonia, both being significant at 0.01 level. When the absolute minimum concentration in the attraction behavior for the fish is set to be $x$ at $y=1$ in the equations, the concentrations were estimated to be $5 \mu \mathrm{mol}$ in histidine and $0.0007 \mu \mathrm{mol}$ in ammonia. Assuming that the compounds were diffused in water $(10.5 l)$ of each test compartment in the experimental aquarium $^{2)}$ and the diffusates reached to the fish, the threshold values in histidine and ammonia were calculated to be $5 \times 10^{-7} \mathrm{M}$ and $7 \times 10^{-11} \mathrm{M}$, respectively. This shows that ammonia is much more effective in the attraction than histidine. The threshold value in histidine accorded well with that of yellowtail ${ }^{3)}$ and coincided roughly with those of various kinds of amino acids obtained electrophysiologically. ${ }^{24)}$

\section{Acknowledgement}

The author is grateful to Dr. H. MAÉDA for his help in the statistical analysis.

\section{References}

1) K. Harada and I. Ikeda: Bull. Japan. Soc. Sci. Fish., 50, 617-622 (1984).

2) K. HaRAda, H. MaÉda, and K. Kobayashi: Bull. Japan. Soc. Sci. Fish., 48, 21-29 (1982).

3) K. Harada: Bull. Japan. Soc. Sci. Fish., 51, 453-459 (1985).

4) J. M. Shewan: in "The Biochemistry of Fish" (ed. by R. T. Williams), Cambridge University Press, Cambridge, 1951, pp. 28-48.

5) J.A.C. Nicol: Biology of Marine Animals, Pitman Paper Backs, England, 1967, pp. 276-301.

6) R. M. Love: The Chemical Biology of Fishes, Academic Press, London and New York, 1970, pp. 129-168.

7) K. Harada： J. Shimonoseki Univ. Fish., 23, 163241 (1975).

8) Y. Obata, T. Yamanishi, and A. Ishida: Bull. Japan. Soc. Sci. Fish., 15, 551-553 (1950).

9) D. M. Steven: J. Exptl. Biol., 36, 261-280 (1959).

10) H. KLeERekoper and J. A. Morgensen: Physiol. Zool., 36, 347-360 (1963).

11) H. Kleerexoper and J. A. Morgensen: $Z$. Vergl. Physiol., 42, 492-500 (1959).

12) W. E.S. CARR: Comp. Biochem. Physiol, 55A, 153-157 (1976). 
13) A. M. MAckie and J. W. Adron: Comp. Biochem. Physiol., 60A, 79-83 (1978).

14) S. Fuke, S. Konosu, and K. INA: Bull. Japan. Soc. Sci. Fish., 47, 1631-1635 (1981).

15) S. Murofusht, A. Asano, and K. Ina: J. Agric. Chem. Soc. Japan, 56, 255-259 (1982).

16) Y. Hashimoto, S. Konosu, N. Fusetan, and T. Nose: Bull. Japan. Soc. Sci. Fish., 34, 78-83 (1968).

17) W. E.S. CARR, A. R. GoNDECK, and R. L. Delanoy: Comp. Biochem. Physiol., 54A, 161166 (1976).

18) W. E.S. CARR and T.B. Chaney: Comp. Biochem. Physiol., 54A, 437-441 (1976).

19) W. E. S. Carr, K. M. Blumenthal, and J. C.
Netherton: Comp. Biochem. Physiol., 58A, 69-73 (1977).

20) A. M. MACKIE, J. W. ADRon, and P. T. Grant: J. Fish. Biol., 16, 701-708 (1980).

21) M. TAKedA: in "Chemical Sense of Fish and Feeding Stimulants" (ed. by Japan. Soc. Sci. Fish.), Koseisha Koseikaku Co., Tokyo, 1981, pp. 109-119.

22) A. M. Mackie and A. I. Mitchell: J. Fish. Biol., 22, 425-430 (1983).

23) R. Kobayashi: Sokan Kaiki Bunseki Nyumon, Nikkagiren Co., Tokyo, 1981, pp. 47-58.

24) T.J. HaRA: in "Chemoreception in Fishes" (ed. by T. J. Hara), Elsevier Sci. Pub. Co., Amsterdam. 1982, pp. 135-157. 